\title{
Nasal Cavity and Ethmoid Sinus Cancer pT4b TNM Finding v8
}

National Cancer Institute

\section{Source}

National Cancer Institute. Nasal Cavity and Ethmoid Sinus Cancer pT 4b TNM Finding v8. NCI Thesaurus. Code C133048.

Nasal cavity and ethmoid sinus cancer with very advanced local disease. Tumor invades any of the following: orbital apex, dura, brain, middle cranial fossa, cranial nerves other than maxillary division of trigeminal nerve (V2), nasopharynx, or clivus. (from AJCC 8th Ed.) 